\title{
INFLUÊNCIA DO MACHEAMENTO DO ORIFÍCIO PILOTO NOS PARAFUSOS CERVICAIS ANTERIORES
}

\author{
INFLUENCE OF TAPPING THE PILOT HOLE IN ANTERIOR CERVICAL SCREWS \\ INFLUENCIA DEL TALADRAMIENTO DEL AGUJERO PILOTO EN TORNILLOS \\ CERVICALES ANTERIORES
} Patrícia Silva ${ }^{1}$, João Paulo Chieregato Matheus ${ }^{2}$, Rodrigo César Rosa ${ }^{3}$, Maximillano Aguiar Porto ${ }^{4}$, Francisco José Albuqueroue de Paula ${ }^{5}$,
antonio Carlos Shimano ${ }^{6}$, Helton Luiz Aparecido Defino

\begin{abstract}
RESUMO
Objetivo: Analisar experimentalmente a influência do macheamento do orifício piloto nas propriedades mecânicas e na interface osso-implante do parafuso cervical anterior. Métodos: Oito carneiros da raça Santa Inês deslanados foram utilizados no estudo. Nos segmentos vertebrais cervicais de C2-C7 foram realizados orifícios piloto de $2,5 \mathrm{~mm}$, de ambos os lados da vértebra. No lado direto da vértebra foi realizado o macheamento previamente a inserção do parafuso cortical de $3,5 \mathrm{~mm}$, e no lado esquerdo o implante foi colocado sem o macheamento do orifício piloto. Foram realizados ensaios mecânicos para avaliar a força de arrancamento dos implantes e estudo histomorfométrico da interface osso-implante na fase aguda e oito semanas após a colocação dos implantes. O torque de inserção foi mensurado durante a colocação dos implantes. Resultados: O torque de inserção e a resistência ao arrancamento dos implantes foram maiores nos implantes colocados sem o macheamento do orifício piloto. A interface osso-implante apresentou maior área de contato ósseo e maior área óssea no interior da rosca do implante nos parafusos implantados sem o macheamento prévio. Não foi observado diferença na área óssea fora do passo de rosca do implante. Conclusões: O macheamento do orifício piloto reduz o torque de inserção e a resistência ao arrancamento do implante na fase aguda e crônica, e reduz a área de contato osso-implante e área de osso no interior do passo de rosca.
\end{abstract}

Descritores: Fixação de fratura; Coluna vertebral; Parafusos ósseos; Histologia; Macheamento.

\begin{abstract}
Objective: Experimentally analyze the influence of the pilot hole tapping on the mechanical properties and the bone-implant interface of anterior cervical screw. Methods: Eight shorn Santa Inês sheep were used in the study. In cervical segments C2-C7 of the column 2.5mm pilot holes were made on both sides of the vertebra. On the right side of the vertebra tapping was done before the insertion of the cortical screw of $3.5 \mathrm{~mm}$, and on the left side the implant was placed without tapping the pilot hole. Mechanical assays were performed to assess the strength of pullout as well as a histomorphometric study of bone-implant interface during the acute phase and eight weeks after implant placement. The insertion torque was measured during implant placement. Results: The insertion torque and pullout strength were higher for implants placed without tapping the pilot hole. The bone-implant interface showed greater area of bone contact and greater bone area within the implant thread on the screws implanted without prior tapping. No differences were observed in the bone outside the thread pitch of the implant. Conclusions: Tapping the pilot hole reduces insertion torque and pullout strength of the implant in both acute and chronic phases, and reduces the area of bone-implant contact and the bone area within the thread pitch.
\end{abstract}

Keywords: Fracture fixation; Spine; Bone screws; Histology; Tapping.

\section{RESUMEN}

Objetivo: Para estudiar experimentalmente la influencia del taladramiento del agujero piloto sobre las propiedades mecánicas y la interfaz hueso-implante del tornillo cervical anterior. Métodos: Ocho ovejas Santa Ines fueron utilizadas en el estudio. En los segmentos vertebrales cervicales C2-C7 se hicieron agujeros pilotos de 2,5 $\mathrm{mm}$ en ambos lados de la vértebra. En el lado derecho de la vértebra el taladramiento se hizo antes de la inserción del tornillo cortical de 3,5 mm, y en el lado izquierdo el implante fue colocado sin el taladramiento del agujero piloto. Se realizaron ensayos mecánicos para evaluar la fuerza de retirada y el estudio histomorfométrico de la interfase hueso-implante en la fase aguda y ocho semanas después de la colocación del implante. El torque de inserción se midió durante la colocación del implante. Resultados: La fuerza de torsión de la inserción y la resistencia a la extracción fueron más altas en los implantes colocados sin el taladramiento del agujero piloto. La interfaz hueso-implante presentó mayor área de contacto con el hueso y mayor área de hueso dentro de la rosca del implante en los tornillos implantados sin taladramiento previo. No se observaron diferencias en el hueso fuera del paso de la rosca del implante. Conclusiones: El taladramiento del agujero piloto reduce el par de torsión de inserción y la resistencia a la extracción del implante en las fases aguda y crónica, y reduce el área de contacto hueso-implante y el área ósea en el interior del paso de la rosca.

\section{Descriptores: Fijación de fractura; Columna vertebral; Tornillos óseos; Histología; Taladramiento.}

\footnotetext{
1. Professora Doutora da Universidade Paulista-UNIP, Campus Ribeirão Preto. Fisioterapeuta do Centro Integrado de Reabilitação do Hospital Estadual de Ribeirão Preto, Ribeirão Preto, SP, Brasil. 2. Professor Doutor da Universidade de Brasília-UNB, Campus Ceilândia. Brasília, DF, Brasil.

3. Professor Doutor do Centro Universitário de Araraquara-UNIARA. Araraquara, SP, Brasil.

4. Professor Doutor da Universidade de Fortaleza-UNIFOR. Fortaleza, CE, Brasil.

5. Professor Pós-doutorado do Departamento de Medicina Interna da Faculdade de Medicina da Universidade de São Paulo-USP, Ribeirão Preto, SP, Brasil.

6. Professor Doutor do Departamento de Biomecânica, Medicina e Reabilitação do Aparelho Locomotor da Faculdade de Medicina da Universidade de São Paulo - USP, Ribeirão Preto, SP, Brasil.

7. ProfessorTitular do Departamento de Biomecânica, Medicina e Reabilitação do Aparelho Locomotor da Faculdade de Medicina da Universidade de São Paulo - USP, Ribeirão Preto, SP, Brasil.
}

Trabalho realizado no Laboratório de Bioengenharia da Faculdade de Medicina da Universidade de São Paulo - USP, Ribeirão Preto, SP, Brasil.

Correspondência: Helton L. A. Defino. Rua Dornélia de Souza Mosca, 235, Jardim Canadá - 14024-12 - Ribeirão Preto, SP, Brasil. E-mail: hladefin @ fmrp.usp.br 


\section{INTRODUÇÃO}

A fixação anterior da coluna cervical tem sido utilizada para fornecer estabilidade mecânica ao segmento vertebral durante o processo de consolidação da artrodese ${ }^{1}$. Essa estabilidade depende de vários fatores tais como densidade mineral óssea, torque de inserção e força de arrancamento do parafuso ${ }^{2-5}$. Além disso, a interface osso-implante é descrita como a maior determinante na estabilidade do sistema de fixação vertebral, uma vez que a soltura de um dos implantes fixados na vértebra pode comprometer a ancoragem de todo o sistema ${ }^{3}$.

O macheamento do orifico piloto é um procedimento de rotina quando os parafusos automacheantes ou autoperfurantes não são utilizados. No entanto, poucos estudos abordaram o efeito do macheamento do orifício piloto na interface entre o tecido ósseo e o implante ${ }^{6-8}$.

O objetivo do presente estudo é avaliar experimentalmente o efeito do macheamento do parafuso cortical utilizado na fixação anterior da vértebra baseando nos parâmetros biomecânicos e histomorfométricas nas fases agudas e crônicas, depois de inserção em osso.

\section{MATERIAIS E MÉTODOS}

Os experimentos foram realizados de acordo com as regras de experimentação em animais e a metodologia foi aprovada pelo Comitê de Ética Local (protocolo 011/2005).

Foram utilizados oito carneiros da raça Santa Inês com a média de peso de $28 \pm 4 \mathrm{~kg}$. Quatro animais foram utilizados na fase aguda, imediatamente a implantação do parafuso, e quatro animais após oito semanas da implantação do parafuso.

As vértebras cervicais de C2-C7 foram selecionados para a implantação dos parafusos. As vértebras C2 a C4 foram utilizadas para a avaliação histomorfométrica e as vértebras C5 a C7 para os ensaios biomecânicos.

$\mathrm{Na}$ face anterior do corpo vertebral foi realizado orifício piloto de ambos os lados da vértebra. O orifício piloto foi realizado com broca de 2,5mm de diâmetro, de acordo com a especificação do fabricante. No lado direito o parafuso era inserido após o macheamento prévio do orifício piloto, e sem macheamento no lado esquerdo.

O parafuso utilizado no estudo era composto de titânio com $14 \mathrm{~mm}$ de comprimento, $3,5 \mathrm{~mm}$ de diâmetro externo e $2,5 \mathrm{~mm}$ de diâmetro interno (Synthes ${ }^{\circledR}$ ) (Figura 1).

A densidade mineral da vértebra foi avaliada por meio do densitometro (DEXA) e utilizando o sistema QDR com a versão11 - 2:5 (Hologic 4500 W, Watham, MA, USA). Foi observada densidade mineral óssea de $0.33 \pm 0.01 \mathrm{~g} / \mathrm{cm}^{3}\left(0.32-0.34 \mathrm{~g} / \mathrm{cm}^{3}\right)$ nas vértebras selecionadas para o estudo.

Todos os procedimentos cirúrgicos foram realizados sob anestesia por meio da injeção intramuscular de xilazina $(0,5 \mathrm{mg} / \mathrm{Kg})$, acepromazina $(0,1 \mathrm{mg} / \mathrm{Kg})$ e ketamina $(2 \mathrm{mg} / \mathrm{kg})$ para a indução, e manutenção por meio da solução de ketamina(1g), xilazina(100g)

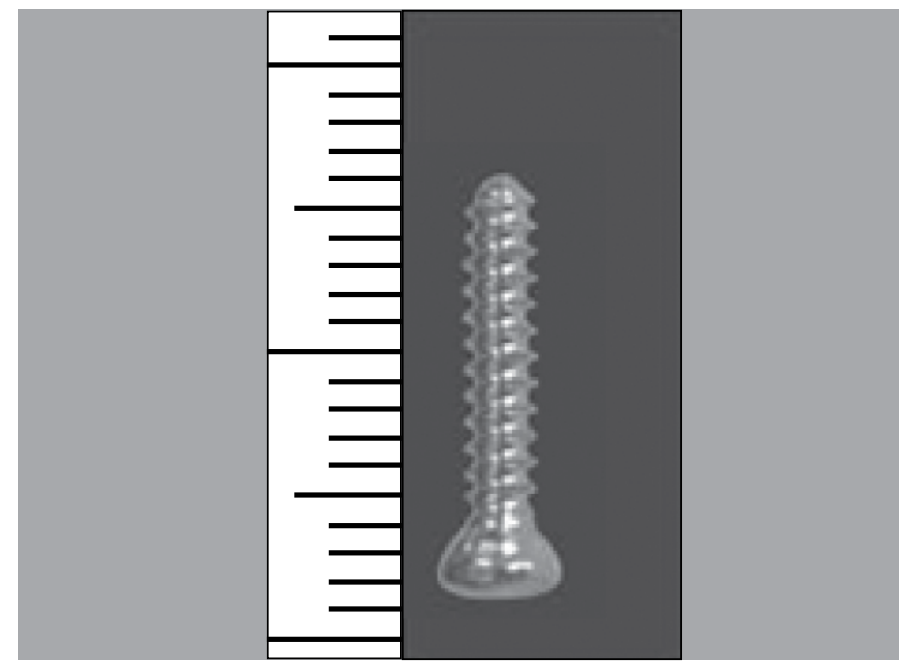

Figura 1. Parafuso utilizado no estudo. e egg (ether gliceril guaiacolico - 50g) em infusão salina venosa $(3 \mathrm{~mL} / \mathrm{Kg} / \mathrm{h})$ durante o procedimento. Os ensaios biomecânicos consistiram na mensuração do torque de inserção e da força de arrancamento dos implantes. O torque de inserção do parafuso foi mensurado por meio de torquímetro (Mackena ${ }^{\circledR}$ TL-500/MKMT-1Brazil), e considerado o valor do maior torque durante a inserção.

O teste de resistência ao arrancamento foi realizado com a máquina universal de testes $\operatorname{Emic}^{\circledR}$ (DL 10000, Brazil) com célula de carga com capacidade de 2000 N. A velocidade de tração axial foi $2 \mathrm{~mm} / \mathrm{min}$, com pré-carga de $50 \mathrm{~N}$.

A análise histomorfométrica foi realizada por meio da microscopia eletrônica de varredura (MEV). Para realização da MEV nos implantes, todo material ósseo excedente a um centímetro quadrado dos parafusos foi retirado e submetido à fixação química por imersão em solução aquosa de formaldeído a 10\% durante um mês. Após este período, foi realizado corte longitudinal ao longo do eixo dos parafusos e as peças resultantes foram submetidas a processo de desidratação em bateria alcoólica (etanol PA - Mer$\mathrm{ck}^{\circledR}$ ) de $30^{\circ}, 50^{\circ}, 70^{\circ}, 90^{\circ}, 95^{\circ} \mathrm{GL}$ (15 minutos em cada concentração) e em três passagens de 20 minutos cada um a $100^{\circ} \mathrm{GL}$ em um aparelho de Critical Point Dryer, modelo CPD - 030 (Baltec $\left.{ }^{\circledR}\right)$.

Após a desidratação as amostras foram fixadas a um cilindro de metal com cola Silver Print $\left(\right.$ Baltec $\left.^{\circledR}\right)$ e recobertas em alto vácuo com fina camada de ouro $24 \mathrm{~K}$ em um Sputter Coater, modelo SCD - $050\left(\right.$ Baltec $\left.^{\circledR}\right)$. As observações e eletronmicrografias foram realizadas em um Microscópio Eletrônico de Varredura Jeol - JSM 5200, utilizando-se filmes $120 \mathrm{~mm}$, ISO 125. A captação das imagens foi realizada com aumento de 35x, o que permitiu a observação dos passos de rosca sempre em pares, após a digitalização.

O software de domínio público Image J v.1.35s da Wayne $R$ Rasband National Institutes of Health, USA foi utilizado para a análise quantitativa.

Os parâmetros utilizados para a análise histomorfométrica foram: contato osso-implante (BC), área óssea no interior da rosca do implante (BI) e área óssea fora da rosca do implante (BO) (Figura 2). Em cada região foi definida área total, contendo trabéculas ósseas e área areolar permitindo assim a quantificação.

O estudo estatístico para a comparação dos parâmetros do estudo foi realizado por meio da análise de variância (ANOVA) utilizando o software PROC GLM SAS versão 9, com um nível de significância de $5 \%(p \leq 0,05)$.

\section{RESULTADOS}

\section{Torque de inserção}

O torque de inserção dos parafusos sem o macheamento prévio foi significantemente maior $(0,18 \pm 0,051 \mathrm{~N}$.m versus $0.07 \pm 0.035 \mathrm{~N}$.m; $\mathrm{p}<0,001$ ) (Figura 3).

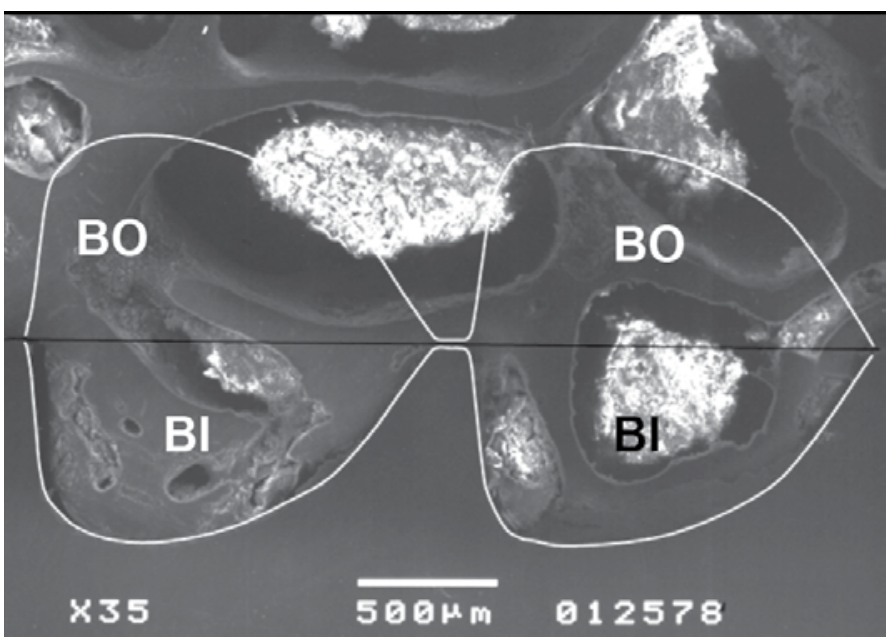

Figura 2. Eletromicrografia de varredura em cortes longitudinais ao eixo dos parafusos: área de osso no interior da rosca do parafuso(BI) e área de osso fora da rosca do parafuso (BO). 


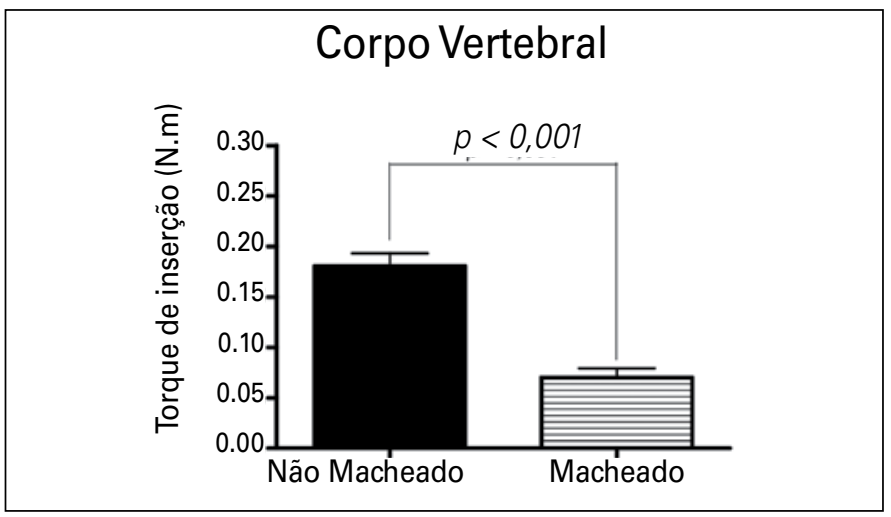

Figura 3. Torque de inserção (média e desvio padrão) dos parafusos com e sem macheamento do orifício piloto.

\section{Resistência ao arrancamento}

A resistência ao arrancamento dos parafusos não macheados foi significantemente maior na fase aguda $(406,04 \pm 12,95 \mathrm{~N}$ vs $356,40 \pm 7,96 \mathrm{~N}-\mathrm{p}<0,01)$ e após oito semanas $(509,49 \pm 167,12$ vs $439,82 \pm 167,41 \mathrm{~N}-\mathrm{p}<0,01$ ) (Figura 4 ).

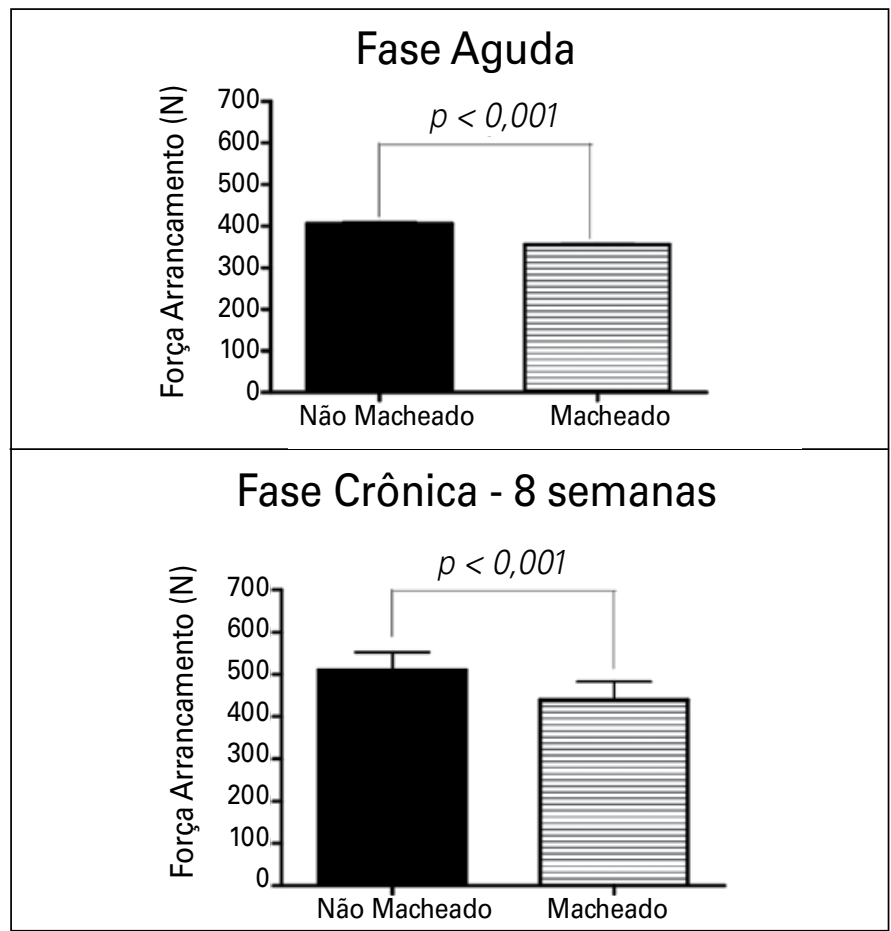

Figura 4. Resistência ao arrancamento (média e desvio padrão) dos parafusos com e sem macheamento do orifício piloto na fase aguda e oito semanas após a implantação.

\section{Histomorfometria}

A área de contato osso-implante foi obtida pela mensuração da superfície de um passo de rosca em 12 parafusos, sendo determinada, dessa forma, a área total de superfície de um passo de rosca em 2,44mm.

Dez analises histomorfométricas foram realizadas em cada etapa do estudo (aguda e crônica). No grupo em que não foi realizado o macheamento foi observado maior contato do tecido ósseo e o implante na fase aguda $\left(0,873 \pm 0,249 \mathrm{~mm}^{2}\right.$ vs $0,672 \pm 0,25 \mathrm{~mm}^{2}$ $\mathrm{p}<0,01)$ e crônica $\left(1.563 \pm 0,193 \mathrm{~mm}^{2}\right.$ vs $1.345 \pm 0.155 \mathrm{~mm}^{2}$ $\mathrm{p}<0,05$ ) (Figuras 5 e 6 ).

A área de osso no interior da rosca do parafuso foi maior na fase aguda e crônica dos parafusos inseridos sem o macheamento, com os valores na fase aguda de $\left(0,282 \pm 0,064 \mathrm{~mm}^{2}\right.$ vs 0,217 $\left.\pm 0,069 \mathrm{~mm}^{2}-\mathrm{p}<0,01\right)$ e de $\left(0,385 \pm 0,054 \mathrm{~mm}^{2}\right.$ vs $0,345 \pm 0,029$ $\mathrm{mm}^{2}-\mathrm{p}<0,01$ ) na fase crônica (Figura 6 e 7).

A área de osso fora da rosca do parafuso não apresentou diferença na fase aguda e crônica da avaliação dos parafusos colocados com e sem macheamento do orifício piloto. Os valores da fase aguda foram $\left(0,239 \pm 0,071 \mathrm{~mm}^{2}\right.$ vs $\left.0,234 \pm 0,040 \mathrm{~mm}^{2}-p>0,5\right)$ e $\left(0,229 \pm 0,049 m^{2}\right.$ vs $\left.0,242 \pm 0,070 m^{2}-p>0,5\right)$ na fase crônica (Figuras 6 e 8).

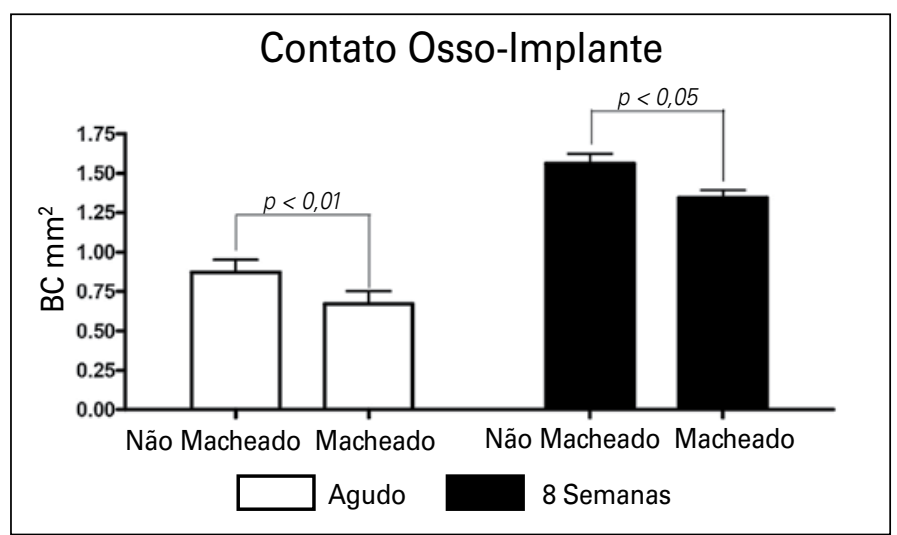

Figura 5. Contato do osso e implante (média e desvio padrão) na fase aguda e crônica dos parafusos colocados com e sem macheamento do orifício piloto.

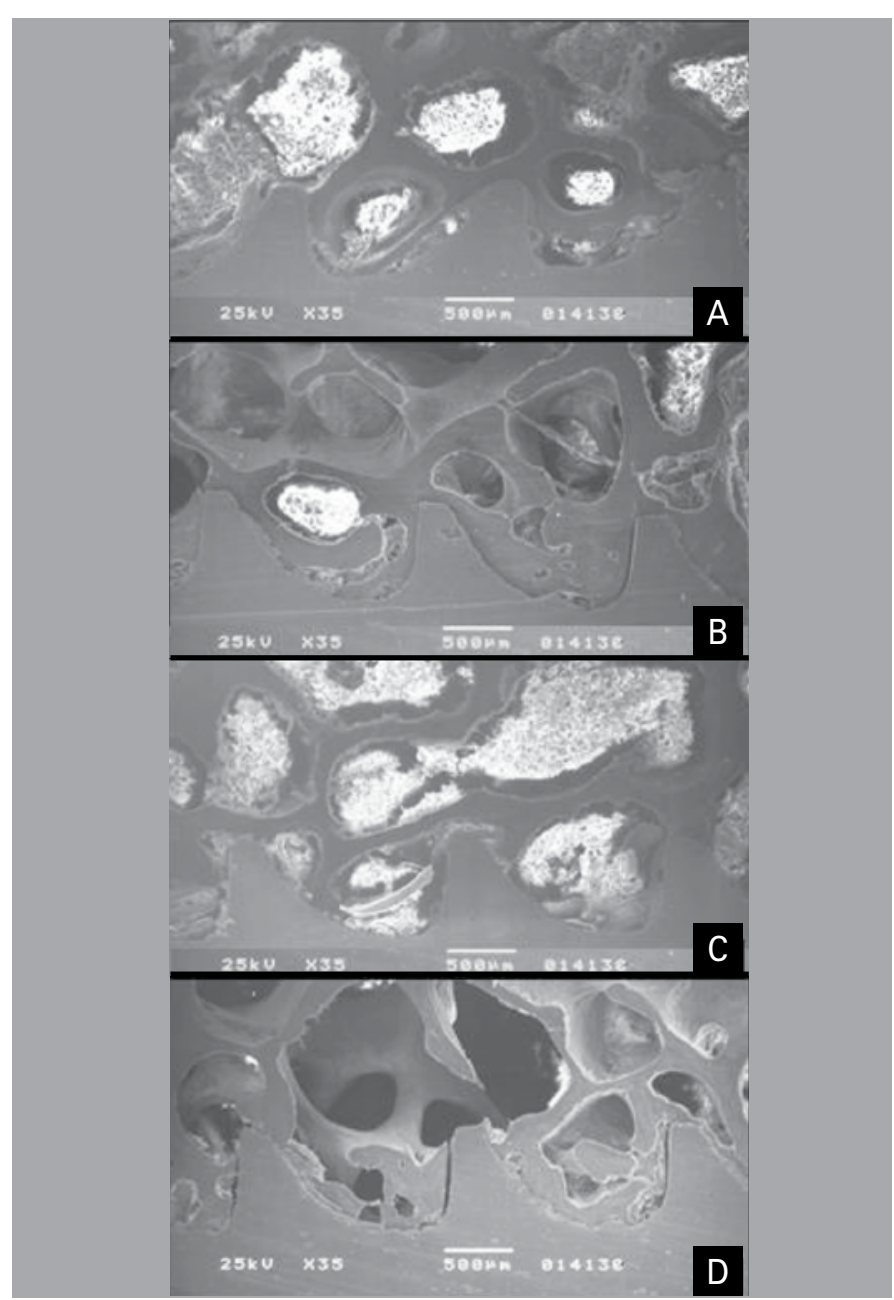

Figura 6. Micrografia da interface osso-implante na fase aguda e crônica. (A) avaliação na fase aguda do orifício sem macheamento; (B) avaliação com oito semanas do orifício sem macheamento; (C) avaliação na fase aguda do orifício com macheamento; (D) avaliação com oito semanas do orifício com macheamento. 


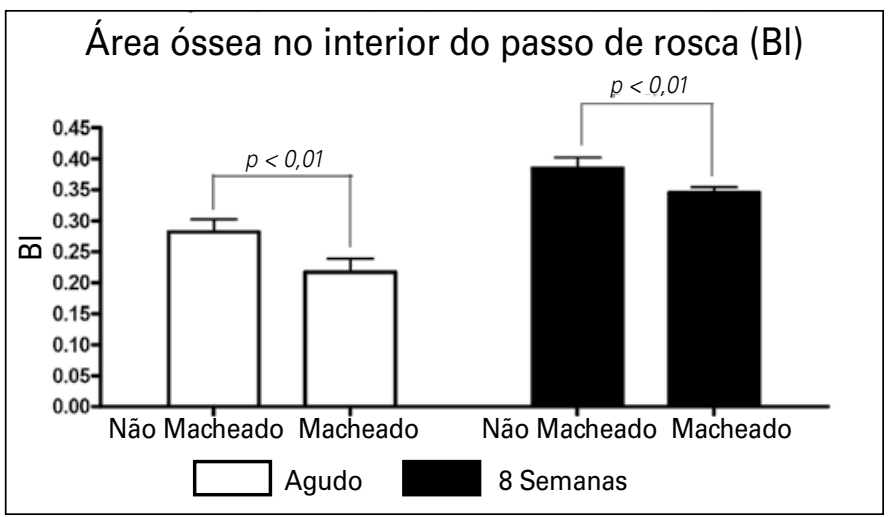

Figura 7. Área de osso no interior da rosca do parafuso (média e desvio padrão) na fase aguda e crônica dos parafusos inseridos com e sem macheamento.

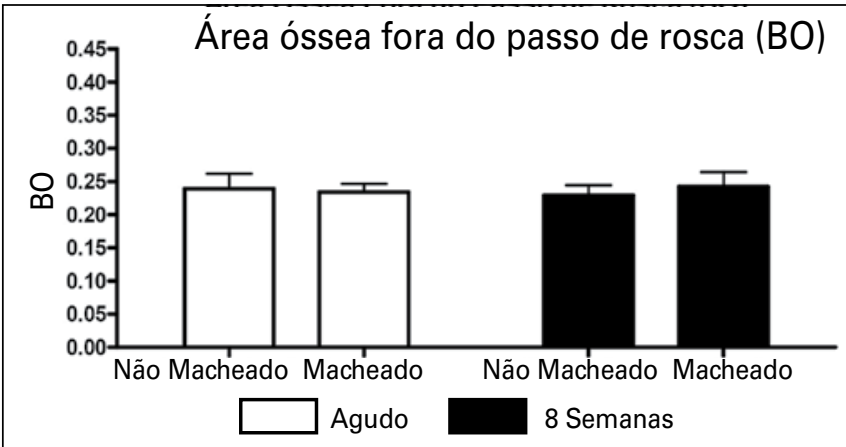

Figura 8. Área de osso (média e desvio padrão) fora da rosca do parafuso na fase aguda e crônica da avaliação

\section{DISCUSSÃO}

O macheamento do orifício piloto promoveu a redução da resistência ao arranchamento na fase aguda e após oito semanas quando comparado com os parafusos introduzidos sem macheamento prévio do orifício piloto. Os parâmetros histomorfométricos da interface osso-implante foram também alterados pelo macheamento do orifício piloto, com destaque para o contato osso-implante e área óssea no interior do passo de rosca.

Os resultados da avaliação mecânica e histomorfométrica indicam que o macheamento do orifício piloto no osso esponjoso do corpo vertebral não apresenta vantagem mecânica e altera a resistência dos implantes ao arrancamento na fase aguda e crônica da sua inserção. A fixação do implante no interior da vértebra é um dos importantes fatores para o bom desempenho da função biomecânica do sistema de fixação ${ }^{9}$. A resistência do implante ao arrancamento pode influenciada pela técnica de inserção, preparo do orifício piloto, desenho da rosca do e parafuso, densidade mi-

\section{REFERÊNCIAS}

1. Dvorak MF, Pitzen T, Zhu Q, Gordon JD, Fisher CG, OxlandTR. Anterior cervical plate fixation: a biomechanical study to evaluate the effects of plate design, endplate preparation, and bone mineral density. Spine (Phila Pa 1976). 2005:30(3):294-301.

2. Conrad BP, Cordista AG, Horodyski M, Rechtine GR. Biomechanical evaluation of the pullout strength of cervical screws. J Spinal Disord Tech 2005;18(6):506-10

3. Hitchon PW, Brenton MD, Coppes JK, From AM, Torner JC. Factors affecting the pullout strength of self-drilling and self-tapping anterior cervical screws. Spine (Phila Pa 1976). 2003;28(1):9-13.

4. Pitzen T, Barbier D, Tintinger F Steudel WI, Strowitzki M. Screw fixation to the posterio cortical shell does not influence peak torque and pullout in anterior cervical plating. Eur Spine J. 2002;11(5):494-9

5. Ryken TC, Clausen JD, Traynelis VC, Goel VK. Biomechanical analysis of bone mineral density, insertion technique, screw torque, and holding strength of anterior cervical plate screws. J Neurosurg. 1995:83(2):325-9.

6. Chapman JR, Harrington RM, Lee KM, Anderson PA, Tencer AF, Kowalski D. Factors affecting the pullout strength of cancellous bone screws. J Biomech Eng 1996;118(3):391-8.

7. Ronderos JF, Jacobowitz R, Sonntag VK, Crawford NR, Dickman CA. Comparative pull-out strength of tapped and untapped pilot holes for bicortical anterior cervical screws. Spine (Phila Pa 1976). 1997;22(2):167-70.

8. Togni F, Baras F, Ribas MO, Taha MO. Histomorphometric analysis of bone tissue repair in rabbits after insertion of titanium screws under different torque. Acta Cir Bras. 2011;26(4):261-6. neral óssea, e pode influenciar no resultado final do tratamento ${ }^{10}$.

Ao contrário do que ocorre no osso cortical da diáfise dos ossos longos, o macheamento do osso esponjoso da vértebra cervical não apresenta vantagens do ponto de vista biomecânico para o sistema de fixação ${ }^{11}$. Carmouch et al. ${ }^{12}$ relataram que o macheamento diminui o torque de inserção e a força de arrancamento do parafuso. No nosso estudo observamos redução da força e da qualidade mineral óssea do tecido ósseo no interior do passo de rosca quando o orifício piloto foi previamente macheado. Na literatura encontramos relatos que o macheamento do orifício piloto diminui a resistência ao arrancamento $7,9,13,14$.

Deve ser considerado que os modelos experimentais utilizando animais não representam a situação clínica real, e que os implantes não foram submetidos à carga durante o período que precedeu a avaliação. No entanto, o tecido ósseo de ovelhas apresenta padrão de crescimento e atividade do tecido ósseo semelhante ao humano ${ }^{15}$.

A densidade mineral óssea das vértebras humanas normais está bem reportada na literatura e variam em média de 0,30 à $0,34 \mathrm{~g} / \mathrm{cm}^{3}$. As vértebras cervicais de carneiros utilizadas no presente estudo são aceitas na literatura como modelo experimental alternativo ${ }^{16}$ e correspondem à densidade das vértebras humanas nãoosteoporótica, com densidade média de 0,33 $\pm 0,01 \mathrm{~g} / \mathrm{cm}^{3}(0,32$ $\left.-0,34 \mathrm{~g} / \mathrm{cm}^{3}\right)$. As vértebras utilizadas no presente estudo possuem densidade mineral óssea dentro dos limites de normalidade, com ausência de osteoporose.

O não macheamento do orifício piloto além de reduzir o tempo cirúrgico estaria associado à melhor fixação dos implantes. As desvantagens do macheamento têm sido bem demonstradas especialmente nos materiais macios e os modernos sistemas de fixação tem sido desenvolvidos para a utilização de parafusos auto-macheantes ou auto-perfurantes, que eliminam o passo técnica do macheamento, reduzindo o tempo cirúrgico e acrescentando ainda vantagens mecânicas ao sistema de fixação.

Os resultados observados evidenciaram que a utilização do macheamento antes da colocação dos parafusos na face anterior do corpo vertebral das vértebras cervicais reduz a resistência ao arranchamento dos parafusos e altera de modo desfavorável os parâmetros histomorfométricos da interface entre o osso e o implante na fase aguda e crônica após a inserção do implante, devendo ser evitada.

\section{CONCLUSÕES}

O macheamento do orifício piloto reduziu o torque de inserção do implante, a força de arrancamento, e alterou a interface osso-implante com redução na superfície de contato osso-implante e área óssea dentro do passo de rosca na fase aguda e oito semanas após a colocação dos implantes.

\section{AGRADECIMENTOS}

Agradecemos o auxílio da CAPES e da FAEPA para a realização do trabalho.

9. Öktenoglu BT, Ferrara LA, Andalkar N, Özer AF, Sarioglu AC, Benzel EC. Effects of hole preparation on screw pullout resistance and insertional torque: a biomechanical study. J Neurosurg. 2001:94 (Suppl 1):91-6.

10. Brantley AG, Mayfield JK, Koeneman JB, Clark KR. The effects of pedicle screw fit. An in vitro study. Spine (Phila Pa 1976). 1994;19(15):1752-8.

11. Ansell $\mathrm{RH}$, Scales JT. A study of some factors which affect the strength of screws and their insertion and holding power in bone. J Biomech. 1968;1(4):279-302.

12. Carmouche JJ, Molinari RW, GerlingerT, Devine J, Patience T. Effects of pilot hole preparation technique on pedicle screw fixation in different regions of the osteoporotic thoracic and lumbar spine. J Neurosurg Spine. 2005;3(5):364-70.

13. Daftari TK, Horton WC, Hutton WC. Correlations between screw hole preparation, torque of insertion, and pullout strength for spinal screws. J Spinal Disord. 1994;7(2):139-145.

14. Skinner R, Maybee J, Transfeldt E, Venter R, Chalmers W. Experimental pullout testing and comparison of variables in transpedicular screw fixation. A biomechanical study. Spine (Phila Pa 1976). 1990;15(3):195-201.

15. Liebschner MA. Biomechanical considerations of animal models used in tissue engineering of bone. Biomaterials. 2004:25(9):1697-714

16. Wilke HJ, Kettler A, Claes LE. Are sheep spines a valid biomechanical model for human spines? Spine (Phila Pa 1976). 1997;22(20):2365-74. 